\title{
THE CHALLENGES OF DEMENTIA CARE AND THE (UN)MAKING OF MEANING: ANALYSIS OF AN ONLINE FORUM ON CARER SPIRITUALITY
}

\section{Peter Kevern and Hans Stifoss-Hanssen}

\begin{abstract}
Although one writer has called dementia "the theological disease", there has been remarkably little research on how people with dementia and their carers find spiritual meaning and significance in their experience. While there is a significant body of literature examining the role of existing spiritual or religious beliefs and practices in supporting the carer of a person with dementia, there is very little research which offers an insight into the reverse process: how the experience of caring challenges a carer's sources of spiritual or religious meaning, and what strategies are adopted to resolve the experienced tension between belief and experience.
\end{abstract}

The present study aimed to supplement this incomplete picture by examining the archive of an online forum responding to a request for "thoughts which lend a spiritual perspective to going through dementia". Interpretative Phenomenal Analysis (IPA) was undertaken on two levels. First, attention was focussed on the forum as an integrated discussion, identifying its recurrent and superordinate themes. The contributions of selected individual participants were then analysed to further examine the way in which their positions were developed.

The analysis uncovered the importance which at least some carers of people with dementia attached to spiritual perspectives, as supplying strength for and meaning to the challenges they faced; but also how meaning was undermined by their experience. Few participants identified with traditional religious resources, but attempted to find meaning by reflection on their personal narrative. Six distinct types of response to the initial question were identified.

These findings indicate that the wellbeing and resilience of at least some carers may benefit from validation of their spiritual concerns along with sensitive and attentive spiritual support. In this task, a key resource is their reflection on their personal narrative in relation to current challenges. 


\section{Keywords}

Dementia; Alzheimer; carer; meaning; spiritual; religion; online; forum; discussion

\section{Acknowledgements}

Thanks to Harriet Dew, Forum Moderator for the Alzheimer's Society, for serving as the ethical 'gatekeeper' and custodian of the material under analysis. Her guidance and cooperation were invaluable in the preparation of this paper. 


\section{THE CHALLENGES OF DEMENTIA CARE AND THE (UN)MAKING OF MEANING: ANALYSIS OF AN ONLINE FORUM ON CARER SPIRITUALITY}

\section{Introduction}

The experience of living with dementia may bring about a crisis of meaning, both for the person living with dementia and their carers (Albinsson and Strang, 2003). Crisis of meaning is in turn correlated with distress, depression and suicidality in some sectors of the population, and therefore requires some attention (Damásio and Koller, 2015; Schnell, Gerstner and Krampe, 2018). For some carers of people with dementia, the experience may present itself as a challenge to deeply-held religious or spiritual beliefs; others may look to established religious or spiritual practices to orientate, comfort or strengthen them, and find them inadequate to the task (Desai and Pargament, 2015). Either situation may give rise to an existential struggle, which in turn may lead to positive attempts to recover a sense of meaning and purpose: for this reason one writer has called dementia "the theological disease" (Keck, 1996). To support carers in this existential task, it is necessary to gain insight into the ways in which they may experience a challenge to their sense of meaning and purpose, and the strategies they use to address it.

While there have been a number of studies which focus on the ways in which carers' spiritual or religious resources may positively or negatively affect their resilience and experience, there is very little analysis of the reverse process: the ways in which the experience of caring for a person with dementia affects the carer's religious or spiritual beliefs and practices; and the ways in which a carer may respond.

The need for this research is apparent from an examination of the available literature. A significant amount of research has been conducted that demonstrates that levels of spirituality or religiosity are significant predictors of outcomes such as caregiver stress and burden (e.g. Heo \& Koeske, 2013; Lopez, Romero-Moreno, Marquez-Gonzalez, \& Losada, 2012; Rathier, Davis, Papandonatos, Grover, \& Tremont, 2015; Sun \& Hodge, 2014). However, there is very little literature which examines how religious or spiritual support is compromised by the experience of caring and reconstructed by carers. This is a significant lacuna: without understanding of the way in which carers may struggle to maintain a sense of meaning and purpose, or understanding of how existential as well as practical challenges may affect their experience of caring, there is little 
to inform the provision of spiritual or religious support to maintain their caring role.

The current study will address this deficit by the examination and analysis of a unique dataset of responses to an online forum. The forum, hosted by the Alzheimer's Society in 2013, began with a contributor who asked for what she called "thoughts which lend a spiritual perspective to going through dementia". Responses range widely and include accounts of unbelief or lost belief in the hope of finding spiritual meaning, links or references to a range of spiritual resources and descriptions of mystical experiences.

\section{Review of research}

To establish the current state of research and so the potential contribution of the present study, a scoping review of the available literature was conducted. Data collection was undertaken between $15^{\text {th }}$ and $20^{\text {th }}$ September 2017 on Scopus, Proquest and CINAHL (see Table 1). After filtering and removal of duplicates, 89 results were retrieved, of which 26 were discarded as irrelevant (mostly because they lacked any empirical research) on detailed reading. Of the remaining 65 papers, 46 were intervention or correlational cohort studies linking spirituality to psychological or social measures of carer wellbeing. Although this is an important field of study, these papers were set aside because they did not shed light on the process of meaning-making except, arguably, through the proxy measures of wellbeing used. This left only 17 papers for inclusion in the review (Table 1). Methodologically, of the 17 papers retrieved, 12 were interview-based (three of which examined different findings from the same interviews in one study); three used focus groups; one was questionnaire-based; and one used an ethnographic combination of observation and interview. In only three studies was spirituality or religion (S/R) the focus of the investigation (Acton \& Miller, 2003; Smith, 2001; Stuckey, 2003). In all others, the theme of S/R was incidental to or subordinate to the express aim of the study. This is important, as it minimizes the risk of recruitment bias: studies which expressly recruit for a study on spirituality may select for those with a positive interest and expertise in the topic, and so overlook the negative and challenging experiences of carers. However, it also means that questions of religion or spirituality were incidental, and the answers were likely to lack depth. 


\begin{tabular}{|l|l|l|l|l|}
\hline $\begin{array}{l}\text { Search string: (dement }{ }^{\star} \text { OR Alzheimer*) AND (spirit* OR Religio*) AND (carer } \\
\text { OR caregiver) in Title, Abstract or Keywords, English language sources only }\end{array}$ \\
\hline Database & $\begin{array}{l}\text { No of hits } \\
\text { (search term } \\
\text { in Title, } \\
\text { Abstract and } \\
\text { Keyword)s }\end{array}$ & $\begin{array}{l}\text { After manual } \\
\text { scan of title } \\
\text { and abstract } \\
\text { for } \\
\text { relevance }\end{array}$ & $\begin{array}{l}\text { After } \\
\text { duplicates } \\
\text { removed }\end{array}$ & $\begin{array}{l}\text { After detailed } \\
\text { reading }\end{array}$ \\
\hline Scopus & 420 & 63 & 89 & Irrelevant 26 \\
\hline Proquest & 35 & 14 & & $\begin{array}{l}\text { Psychometric } \\
46\end{array}$ \\
\hline Cinahl & 150 & 45 & & Retained 17 \\
\hline
\end{tabular}

Table 1: Summary of literature search results

Of the 17 papers, 11 reported on personal spirituality only as a positive factor in supporting or motivating the carer, although three of these (all from the same study) included a reference to negative experiences of religious communities such as rejection or judgement on the carer (Smith, Lauret, Peery, \& Mueller, 2001; Smith, 2001; Smith \& Harkness, 2002). None referred to the challenge that the experience of caring may pose to carer spirituality.

The remaining 6 participant-based papers (Acton and Miller, 2003; Farran, Paun and Elliott, 2003; Paun, 2004; Sanders, 2005; Netto, Jenny and Philip, 2009; Hinton et al., 2010) reported on carers' perceptions of the experience of caring as contributing to their spiritual formation or growth. These considered the relationship between $S / R$ and caring as some sort of dialectic, in which each informs the experience of the other.

However, all these results should be treated with caution. With the exception of the questionnaire-based study $(\mathrm{N}=85)$ the sample sizes were small $(\mathrm{N}=9$ to $\mathrm{N}=12$ ) or unreported, and results were potentially influenced by the presence of the interviewer or focus group leader. This suspicion is supported by the observation that, with the exception of a single reference in Paun's study (Paun, 2004) there was no reference to a reduction or complete loss of spiritual or religious support as a result of the experience of caring. Since this was true of studies where spirituality was an incidental theme as well as those in which it was an explicit focus, it is not likely to be simply attributable to selection bias: we may provisionally conclude that these studies were uncovering and presenting an incomplete picture of carers' religious and spiritual life.

To conclude this survey of the literature, although there appeared on the face of it to be a substantial body of research on the role of $S / R$ for carers of people with 
dementia, the majority of it consisted of correlational studies which shed little light on the nature of the relationship (positive or negative) between S/R and carer wellbeing. Of the 17 qualitative studies identified, only 6 constructed the relationship dialectically, i.e. considered the effect of the experience of caring on carers' spiritual or religious resources as well as vice versa. Of these, 5 were potentially influenced by the presence of the interviewer or focus group leader and the other was a questionnaire-based study. There is therefore a deficit of understanding concerning how carers of people with dementia may construct and reconstruct their spiritual or religious resources in the light of their experience of dementia, in the absence of a facilitator or interviewer who may influence the outcome. The purpose of the current study is to contribute to a more detailed understanding of how carers construct meaning in the light of their experience in the absence of a moderating figure.

\section{The character of the material}

The present study seeks to address a gap in the literature by making use of a different sort of data, from which the researcher is absent at the point of its production and is therefore unable to either actively or passively influence its form and content. The material analysed here was generated as a forum topic on the web-based discussion board Talking Point, hosted by The Alzheimer's Society UK in February-March 2013

The particular contributions of research data of this type derive both from its format and its content. In terms of format, the fact that replies may be of any length, and may either respond to a previous reply or to the original question, allow for a form of expression which falls midway between an autobiographical account and a response to an interview question; in addition, the nature of onscreen conversation favours immediate and spontaneous replies rather than carefully thought-out responses (Kozinets, 2015). In terms of content, the fact that anybody may contribute to an open-ended discussion avoids some of the selection bias that is inevitable in interview studies of the subject, while providing more focus than ones in which spiritual or religious meaning-making emerges as one theme among others. We postulated, therefore, that an analysis of the data would provide some new insights into the ways in which carers of people with dementia experience threats to spiritual meaning, and the strategies they may use to address this deficit. 


\section{Methodology and Methods}

The overwhelming majority of studies of online forums have taken the form of a simple content analysis, treating each contribution as a unit of analysis and searching within and between units for emerging themes (e.g. Fabrício et al., 2011; Holtz et al., 2012; Im \& Chee, 2006). However, there has been increasing interest in a forum post as a distinct rhetorical genre which differs from both conversation and print media. A number of recent studies have employed tools derived from conversation analysis or critical discourse analysis to attempt to capture some of the social dynamics underlying the content of online forums (Jowett, 2015; Kaufman and Whitehead, 2016; Paulus, Warren and Lester, 2016). For the purposes of the current study, analysis followed the principles of Interpretative Phenomenological Analysis (IPA), adapted to take account of the unique features of a forum of this type.

IPA lends itself to studies of meaning-making by individuals. It employs the principle of a 'double hermeneutic': in this case, the researchers are interpreting the participants' own attempts to make sense of spirituality/religion in the context of dementia (Smith, Flowers, \& Larkin, 2009). In accordance with this principle, the material was analysed twice. Since the researchers were in different countries (UK and Norway) they worked on identical transcripts drawn from the archived version of the forum available through the Alzheimer's Society website. For each stage, the researchers undertook an initial analysis independently, then conferred by Skype and email to agree a shared account of the material. For the first stage, the material was examined as a sequence of contributions to a conversation: this overview approach sensitized us to the interactions between individuals, and so to identify decisive developments in the discourse. The process yielded key themes that could be extracted for analysis: the authors independently reread the transcripts line-by-line to extract recurrent, salient themes relating to the forum's original questions; then they worked collaboratively to identify superordinate themes defining the overall structure of the conversation.

For the second stage, the authors investigated how these themes interacted in the work of meaning-making by a detailed analysis of the forum posts of particular individuals whose contributions exemplified the development of distinct themes (see Pietkiewicz \& Smith, 2014). A 'shortlist' of seven contributors was agreed upon who had (a) made a contribution to the forum which was sufficiently substantial to allow detailed study and (b) discussed one or more of the key themes identified in stage one. The process of meaning-making in each of the case studies was teased out by discussion between the two researchers, and 
presented in the form of short summaries (see below). On the basis of the findings from this two-stage process, a model was generated of the interrelationship of key themes running through the material.

As in any qualitative analysis, the researchers' own perspectives should be made explicit and analysed reflexively for their contribution to the findings. In the current study, both researchers have published (independently) other work at the interface of spirituality or religion and health; and they share a view that spiritual or religious beliefs and practices may have both positive and negative influences on the experience of health and illness. However, in the current study the decision was made to work within the constraints of the forum itself: i.e. the definition of spirituality or religion would be participant-led, and include whatever participants considered a relevant answer to the call for "thoughts which lend a spiritual perspective to going through dementia". The formulation of the original call further implied that (a) a spiritual perspective is possible; and (b) it influences one's view of "going through dementia", hence having some existential or hermeneutical significance. These statements were therefore also adopted as necessary prior assumptions.

\section{Ethics}

The design of this research project was as an observational study of a social interaction taking place within the public domain, and at the time of writing the entire forum is publicly available for scrutiny on the web. However, while online forums may technically be in the public domain, they may not be perceived to be so by participants (Eysenbach and Till, 2001; Elgesem, 2002). In our analysis we have followed the guidance of the British Psychological Society (British Psychological Society, 2017) that, in a context where the distinction between public and private is liable to be blurred, particular care should be taken not to further disclose potentially sensitive information.

Accordingly, before gaining approval from the University Ethics Committee, prior approval in principle was sought and granted by the forum moderator on behalf of the Alzheimer's Society UK. Once the paper was drafted, the forum moderator contacted all the participants to ask them if they would be willing for their words to be quoted directly in a forthcoming research paper. Since only two of these (participants $\mathrm{B}$ and $\mathrm{O}$ ) were available and willing to give explicit permission, we decided in discussion with the forum moderator to remove all the quotes with the exception of very short (10 words or less) in-text phrases where a paraphrase might distort the meaning. At the moderator's request, we state that "We 
approached Alzheimer's Society for permission to use quotes of service users, and have ensured that their identity is protected"

\section{Analysis}

The forum, entitled Spiritual Aspects of Dementia, comprised 64 posts contributed by 25 individuals between $23^{\text {rd }}$ February and $8^{\text {th }}$ March 2013. 62 of these posts were contributed over a single week, from $23^{\text {rd }}$ February to $1^{\text {st }}$ March. The remaining two posts were added after a delay of a week, and attracted no further comment. They have therefore been excluded from this analysis. The dialogue was, therefore, short but intense: although more extended than a focus group, and involving many more contributors, it maintained the characteristics of a shared and mutually-responsive discussion. This can be seen in the fact that, of the 62 posts analysed, 29 (47\%) explicitly referred to a previous post. The tone was uniformly courteous: there were no incidences of ridicule or parody, although there were occasions where contributors clearly disagreed.

The level of involvement varied widely among contributors. Twelve of the contributors made only one post, six made two each. The length of individual posts ranged from just 6 words to 1009 words long. The longest combined contribution (aggregating their posts) by a single contributor was 2002 words, representing some $13 \%$ of the total; the most prolific contributor posted 12 times (19\% of the total). Thus, the forum was characterized by some extended thinking and repeated engagement from a small number of individuals.

Eleven contributors gave their place of residence as in the UK; 3 in Canada; one in France; and 8 did not include the information. Of the 12 participants who declared a position, only one claimed to be a mainstream Christian; 5 could be classed as 'spiritual, not religious'; 5 declared themselves to be neither religious or spiritual (with 3 of these self-identifying as atheist) and one declared herself to be 'confused'. But quite a few of the posts were written with a background in Ireland, and with references to the Catholic Church. In all these instances, the reference serves as a negative marker. There was therefore no reason to assume that the conversation would take a conventionally religious course or remain restricted to traditional doctrinal positions. 
Longer posts generally followed a similar form:

1. A 'position statement' of where somebody stands in relation to spirituality and religion. These tended to be included in the first or second post by an individual (12/23 participants).

2. An affirmation of a previous poster or endorsement of their content. These were, naturally, more prevalent in later posts (29/62 posts).

3. A testimony or narrative which both established the poster's authority to speak and provided the basis for an 'argument' (which may be elaborated over successive posts) (29/62 posts)

4. A reflection on the narrative which provided a conclusion

Viewed as a whole, the exchange falls naturally into three broad phases. In posts $1-19$, there were many new contributors (13 of the 25 contributed at this stage) and more than half of them (7/13) began their contribution with a 'position statement' declaring the perspective they brought. Posts 20-50 represented the mid stage of the exchange. 8 new contributors joined the conversation in this stage, but it was dominated by a succession of longer, narrative posts and, increasingly, more theoretical or even theological posts which strayed from the presenting questions to broader questions of punishment, forgiveness and abuse. Finally, posts 51-64_represented an 'end stage'. With the exception of the last two posts (which were added a whole week later and attracted no comment) only two new participants joined at this stage, contributing short comments. The exchange was dominated by one individual's claims to a special revelation: the exchange of divergent ideas was effectively over.

\section{Thematic analysis}

This stage of the analysis was conducted over the period from December 2017 to February 2018. The two authors independently coded the material, then collaborated over Skype to develop a shared list of key subordinate and superordinate themes.

For the analysis, contributors were each assigned a code letter ( $A-X)$. Individual posts were numbered sequentially from 1-62: the post number appears in brackets after a reference to specific content.

The thread was entitled Spiritual Aspects of Dementia and initiated by A, who requested (in her words) "thoughts which lend a spiritual perspective to going through dementia". Although the post reads as very spontaneously written, on analysis it reveals a structure which sets the parameters for the exchange, in the following ways:

1. The basic request, is couched in dialectical terms. A is encountering a dissonance between her 'spiritual' expectation of justice and her experience of 
caring for a close relative with dementia. She protests that the relative does not deserve what A perceives as her suffering, and that she is struggling to find meaning in it.

2. The envisaged responses she offers are narrowed down to four possibilities:

a. Whether there are any lessons to be learned by reflecting on the caregiver's 'journey'

b. Whether there are any lessons to be learned by reflecting on the 'journey' of the person with dementia

c. Whether other participants have spiritual perspectives that they find give them strength

d. Whether other participants have spiritual perspectives that help them to make sense of the experience

Remarkably, the theoretical framework implicit in this post is reproduced in the responses. Subsequent posters either reject the dialectic altogether or address one or more of the possibilities A outlines. This is apparent in the following thematic analysis: 


\begin{tabular}{|c|c|c|c|c|}
\hline $\begin{array}{l}\text { Theme } \\
\text { Number }\end{array}$ & $\begin{array}{l}\text { Subordinate theme } \\
\text { name }\end{array}$ & $\begin{array}{l}\text { Posts } \\
\text { where } \\
\text { present }\end{array}$ & Expansion of theme & $\begin{array}{l}\text { Superordinate } \\
\text { theme }\end{array}$ \\
\hline 1 & Dissonance/injustice & $\mathrm{A} 1, \mathrm{U} 47$ & $\begin{array}{l}\text { The person with dementia } \\
\text { does not deserve to be } \\
\text { going through this } \\
\text { experience }\end{array}$ & \multirow[t]{2}{*}{$\begin{array}{l}<1>\text { Dialectical } \\
\text { conflict between } \\
r / s \text { and } \\
\text { experience }\end{array}$} \\
\hline 2 & $\begin{array}{l}\text { Failure to make spiritual } \\
\text { meaning }\end{array}$ & $\begin{array}{l}\mathrm{A} 1, \mathrm{~A} 8 \\
\mathrm{U} 47, \mathrm{U} 52\end{array}$ & $\begin{array}{l}\text { Wanting to find some } \\
\text { meaning in the carer } \\
\text { experience, but failing to } \\
\text { do so }\end{array}$ & \\
\hline 3 & $\begin{array}{l}\text { Rejection of dialectic in } \\
\text { special revelation }\end{array}$ & B2, B39 & $\begin{array}{l}\text { A divine being gives the } \\
\text { truth regardless of } \\
\text { experience }\end{array}$ & \multirow[t]{2}{*}{$\begin{array}{l}<2>\text { Rejection of } \\
\text { dialectical } \\
\text { premise }\end{array}$} \\
\hline 4 & $\begin{array}{l}\text { Rejection of dialectic by } \\
\text { rejecting } s / r\end{array}$ & $\begin{array}{l}\text { D6, F9, I13, } \\
\text { J14, K16, } \\
\text { I17, P23, } \\
\text { Q26, I49 }\end{array}$ & $\begin{array}{l}\text { Principled } \\
\text { atheist/humanist position } \\
\text { - rejection of } s / r \text { as it } \\
\text { makes things worse or is } \\
\text { morally repellent }\end{array}$ & \\
\hline 5 & $\begin{array}{l}\text { Spiritual lessons to be } \\
\text { gained }\end{array}$ & $\begin{array}{l}\text { A1, E7, A8, } \\
\text { G10, R31, } \\
\text { E41, E44 }\end{array}$ & $\begin{array}{l}\text { The experience of caring } \\
\text { has forced the carer to } \\
\text { grow spiritually }\end{array}$ & \multirow{4}{*}{$\begin{array}{l}<3>\text { Potential } \\
\text { positive } \\
\text { relationship } \\
\text { between } \mathrm{R} / \mathrm{S} \text { and } \\
\text { carer experience }\end{array}$} \\
\hline 6 & $\begin{array}{l}\text { S/R sources of carer } \\
\text { strength }\end{array}$ & $\begin{array}{l}\mathrm{A} 1, \mathrm{G} 10 \\
\mathrm{O} 21, \mathrm{U} 47\end{array}$ & $\begin{array}{l}\text { A spiritual being or } \\
\text { practice is helping the } \\
\text { carer(s) even if it cannot } \\
\text { be perceived while under } \\
\text { the pressure of caring }\end{array}$ & \\
\hline 7 & $\begin{array}{l}\text { Source of blessedness } \\
\text { for PWD }\end{array}$ & $\begin{array}{l}\text { A1, G10, } \\
\text { A15, M19 }\end{array}$ & $\begin{array}{l}\text { Dementia can bring } \\
\text { peace to the person living } \\
\text { with it, as they 'live in the } \\
\text { moment'. }\end{array}$ & \\
\hline 8 & $\begin{array}{l}\text { Dementia as 'meant' or } \\
\text { Telos }\end{array}$ & $\begin{array}{l}\mathrm{B} 2, \mathrm{O} 21 \\
\mathrm{O} 30, \mathrm{~V} 54\end{array}$ & $\begin{array}{l}\text { Caring as the fulfilment of } \\
\text { life's purpose, which gives } \\
\text { sense to the struggles of } \\
\text { the rest of life }\end{array}$ & \\
\hline
\end{tabular}

Table 2: Thematic analysis and superordinate themes (letters refer to contributor; numbers to contribution number) 
As already noted, A sets up a dialectical problem - that her experience of caring does not correlate with the resources and expectations of her spirituality - and hints at four possible ways in which her question may be posed. According to our thematic analysis, there are six responses identifiable within the forum contributions: four of these are along the lines she anticipated, but two reject her original premises. These last two both take the position that there is no dialectic to be resolved, but for opposite reasons. For some (such as $\mathrm{B}$ ), there is no tension because spiritual truth is immune to challenge from experience: it is given supernaturally. For others (such as I), there is no dialectical tension because 'spiritual meaning' is an oxymoron or a fantasy.

In the following section, we will explore further the initial question and these six patterns of response by a detailed examination of the postings by seven contributors to the forum. Each of them contributed multiple times, and had the opportunity to develop their approach in some detail. They will provide detailed insight into how, within each of these stances, the dialectical tension may be resolved.

\section{Analysis of individual contributors' hermeneutic positions}

This stage of the analysis was conducted during March and April 2018. The successive posts contributed by an individual were combined to provide a conspectus, which was then summarised in a short narrative case study by the two authors working collaboratively. While inevitably subjective, an attempt was made to keep the case studies faithful to the participants' own thoughts: they were based on direct quotations as far as possible, although these were then removed in the final draft and replaced with references in order to preserve participant confidentiality.

\section{Participant A}

Since A initiated this forum conversation, she is inevitably the addressee for a number of the replies. She herself, however, only contributes on four more occasions: twice with a short affirmation of another's contribution $(4,5)$, and twice with more substantial contributions $(8,15)$. The first of these starts by restating the meaninglessness she encounters in caring for her mother: despite her faith that nothing occurs by accident, she can't see the point of her mother's suffering. This experience constitutes an argument for rejecting another contributor's suggestion that the spiritual meaning is to be found in her own spiritual development (8).

The second of her posts is to reject another suggestion: that it is she who is suffering from the experience of observing a person with dementia, rather than 
her mother. She argues that her mother's dementia is clearly observable and cannot be dismissed so easily (15)

$A$ is clearly engaged with and appreciative of the responses she receives (she expresses her thanks to all who contributed in 8, and in particular thanks her protagonist in 15) but encounters nothing in them that would resolve the dialectic with which she opens the forum. On the contrary, the extra detail she supplies in subsequent posts demonstrates that the emotions she experiences caring for her mother will not be resolved by any contributions to this forum. The fact that she leaves the conversation the day after she began it suggests she came to the same conclusion herself; and her final words appear to be 'signing off'. The fact that $A$ does not receive an answer that satisfactorily 'resolves' her problem need not be taken as evidence that she was disappointed or dissatisfied: on the contrary, her appreciation for others' contributions (even if they do not provide the 'answer') suggests that she has found them supportive. Even though the answers they offer may not be persuasive, they are evidence that other participants have grappled with the same issues of $A$; that they understand her dilemma; and that she is not alone in her quest.

\section{Participant B}

B's initial contribution is immediately after the Forum opens (2), but she does not comment again until 3 days later, with post 39. She dominates the closing phase of the conversation with five posts, the last of which is 62 . Although she refers to caring for her mother and then her husband (39) this is not the experience which drives her contributions. The narrative to which she appeals is one in which she has received a special revelation that all is according to God's plan. According to her account, the angel Gabriel spoke to her one night to reassure her that everything was part of God's plan, and that we are all part of God (2). The remaining posts provide 'warrants' for the validity of this message by citing paranormal experiences and the "fundamental truth" of mathematics (e.g. 57): This approach negates the force of the dilemma posed by A: religion may cause confusion, but direct revelation resolves it, as it gives the true meaning that experience may conceal (30) Interestingly, I (see below) does not directly challenge her, although from l's own comments it seems unlikely that she would agree with $\mathrm{B}$. The appeal to special revelation shuts down dialogue.

\section{Participant I}


l's involvement is puzzling. She posts more frequently than any other contributor (12 times), but the posts are short. Her position is as an atheist, which she links to her 'science background'. Consequently, she views her own mother's decline by an analogy to a machine wearing out, piece by piece (13).

I's basic position, like B's, is to reject the premise of A's question: there is no dialectic, because religion/spirituality has nothing to offer. This raises the question of why she is concerned at all. The answer may lie in the fact that she has seen the continuing hold that early religious conditioning has on her partner (42).

This concern seems to drive l's repeated contribution, that worrying about S/R 'meaning' is only a further cause of suffering. She reacts with horror to the notion that an illness might be part of a wider purpose (13). Instead, she argues, concern with 'meaning' may itself be a source of suffering and the original poster would be better advised to let the question go (17).

Hence, l's involvement with the discussion seems to be primarily to challenge religious or spiritual attempts to discern meaning. She offers more direct responses to individuals than the typical participant, and less autobiographical or narrative detail. Her posts can be short and sharp (40) but are not unkind and display some curiosity about others' approaches to the question.

These two contributors ( $\mathrm{B} \& \mathrm{I}$ ) demonstrate positions that reject the premise of the questioner, for opposite reasons. Each declares a position which makes maintenance of the dialectic irrelevant. As such they are the 'outliers' within which the problematic is further defined. The remaining participants each represent an attempt to locate $S / R$ meaning within the lived experience of caring for a person with dementia.

\section{Participant E}

E states that she is not religious, and in the process of moving away from a background in 'canned religion'. Nevertheless, she is one of only two contributors in the material under study who explicitly references a 'theology', albeit not a Christian one. This is the work of Deepak Chopra, in which she finds a message of spiritual evolution which, she claims, informs her experience as a carer of a person with dementia. She says that she is still an atheist but discovering a spirituality. Her experience of caring has forced her to develop the 'Spiritual Domain' of her brain. This development has transformed her life, and she concludes that there is a meaning to the experience of caring despite (or because of) the struggle (7).

This is the position which is challenged by A's second post, as above. However, A's response does not silence $E$, who returns to expand on the topic at a later 
point. She reports that the existential 'stripping' that characterised her experience left her with a sense of peace and inner space (44).

$E$ argues both from the Chopra's book and from her own experience, that spiritual meaning may be found in dementia: but that to perceive it we may need to progress to a higher spiritual level. She also argues that the experience of caring can itself push that evolution, so caring becomes the means as well as the goal of the search for spiritual meaning. Thus, it may be said that she offers a constructive dialectic as an alternative to A's destructive one: instead of seeing the experience of dementia as destructive of spirituality, she proposes that it can drive it and, in turn, the new spiritual perception can make sense of the experience of dementia.

\section{$\underline{\text { Participant } \mathrm{O}}$}

O contributes only five posts, but between them they total nearly 2000 words and make up about $20 \%$ of the total on the forum. They take the form of an autobiography in five substantial instalments, focussing on his childhood, early life, business career and the story of his relationship with his wife.

His early life was one of suffering, being brought up in an Irish orphanage run by nuns, and then a centre run by the Christian Brothers (21). He goes into considerable detail about the hardships he experienced, and then about his later life as husband, father and international businessman

One of the effects of his posts is to divert the discussion away from dementia to a focus on the role of the Catholic Church in Ireland, and stories of childhood abuse. At first sight, therefore, his contribution seems a distraction, and its relationship to the issue in hand elliptical and obscure. However, when viewed as a whole, his successive posts build up to develop a distinct point of view. It stems from his conviction that his wife is the source of his spirituality, and his purpose (50). From this perspective, his childhood suffering has meaning because it gave him the strength and compassion to nurse her throughout her dementia; and the way his wife transformed his life meant he sought the opportunity to give back as generously as he had received $(21,30)$.

Thus for $\mathrm{O}$, caring for his wife with dementia is the climax of his life and its purpose: it is not a period which needs meaning supplied, but the period which in turn confers meaning on his early experiences and present ill-health (30). The novel contribution this extended story brings to the questions posed by $A$ is, in effect, to reverse the terms. Instead of asking, "What spirituality will support a carer of a person with dementia?", he replies, "Caring with compassion for my loved one with dementia is a privilege and the source of my spirituality". 


\section{Participant U}

$\mathrm{U}$ is one of only two participants who explicitly identifies as a Christian of any description, but finds himself immersed in the dialectic through his experience of dementia in his family. Both his grandfather and his grandmother have been diagnosed with a form of dementia. Having begun by praying for them to be well, he came to understand that their condition was irreversible, and prayed for them to be 'at peace'. The implication is that he was praying for them to die peacefully. He has now stopped praying altogether, but is trusting that God will decide when they should die (47)

Although $U$ doesn't know what to pray for, or how prayer might relieve the immediate situation, he maintains his belief that God can and does help. He believes that when he needs God again, God will be there to help him. Thus, although his experience of dementia is preventing $U$ from finding a spirituality he can maintain, his faith that God strengthens and supports people remains undimmed. The resolution of this tension is a matter for faith and hope, rather than immediate experience.

\section{$\underline{\text { Participant G }}$}

G contributes just one post, but a fairly substantial one of 557 words. It is worthy of further examination because it presents in some detail a perspective that nobody else advances in a developed form; and because of the strength of reaction it elicits from some other contributors.

The gist of her position is that the experience of dementia can be a blessing for the person living with it; and that with the right attitude of acceptance it can be a blessing for the carers as well (10). We think that the person with dementia is suffering because we see them from our own point of view; but they might be happy.

Couched in friendly terms, this post represents a challenge to A. It suggests that A's pain is her own pain rather than her mother's: that $A$ is projecting her own pain onto her experience of her mother when she should instead be learning from her mother to trust and be still. This attracts a rebuff from several contributors, who maintain that it is obvious that many people with dementia are very distressed; and that it would be obscene to claim this suffering was all part of a divine plan.

The strength of this reaction perhaps indicates that, for many participants, an attempt to discount carers' own experience of dementia in the search for spiritual meaning is not an option: any attempt to construct meaning must take their practical knowledge into account from the start. 


\section{Discussion}

This study has brought a new perspective on the question of how carers of people with dementia attempt to make sense in their daily challenges. Unlike several of the qualitative studies identified earlier, it does not simply point to positive spiritual resources. Instead, it casts the task of caring as a site of struggle between what may be an experience of meaningless suffering and hopes and desires that there is source of spiritual meaning which relativises or reframes that experience.

Among carers of family members with dementia, there are a number who are sufficiently concerned to find some spiritual meaning in their experience that they will invest energy and thought in an online discussion. Among these, the majority have found that their experience of caring has challenged their existing spiritual or religious interpretations. For some, this has led to the settled conclusion that there is no role for spirituality; or that spirituality is somehow 'revealed' and so independent of day-to-day experience. Others, however, clearly grieve the apparent loss of whatever sense of meaning, purpose or comfort they derived from their spirituality and are actively seeking to reconcile the dialectic between beliefs and experience. It seems that there are two different understandings of spiritual meaning at work here. Posters $B$ and I reject the premise embedded in the original question, treat meaning as an external objective 'given', to be accepted or rejected; the remaining posters analysed here $(E, U, G, O)$ accept the validity of the original question, and deal with meaning as a quality to be found or constructed in reflection upon experience. This distinction is similar to Schnell's distinction between horizontal and vertical meaning (Schnell, 2009). In their search, the traditional resources of institutional religion are unlikely to be of much use - the majority of contributors to this forum had distanced themselves from 'religion', even if they considered themselves 'spiritual'. Almost all seem to have adopted the binary distinction definitively articulated by Heelas and Woodhead between 'religion' as to do with externally-applied rules and rigid social norms; and 'spirituality' as individual, internalized and fluid (Heelas et al., 2005). Nevertheless, it seems clear that, for some carers at least, it is important to talk about the spiritual meaning of their experience, and this may contribute to the positive effect of spirituality on coping and carer burden noted briefly in the review of the literature (see e.g. Lopez et al., 2012; Ravari, Mirzaei, Salamizadeh, \& Askari Majdabadi, 2017; Wilks \& Vonk, 2008). One of the findings from the current study is that there are a number of possible ways to attempt to 'make meaning', which are outlined diagrammatically in Figure 1 


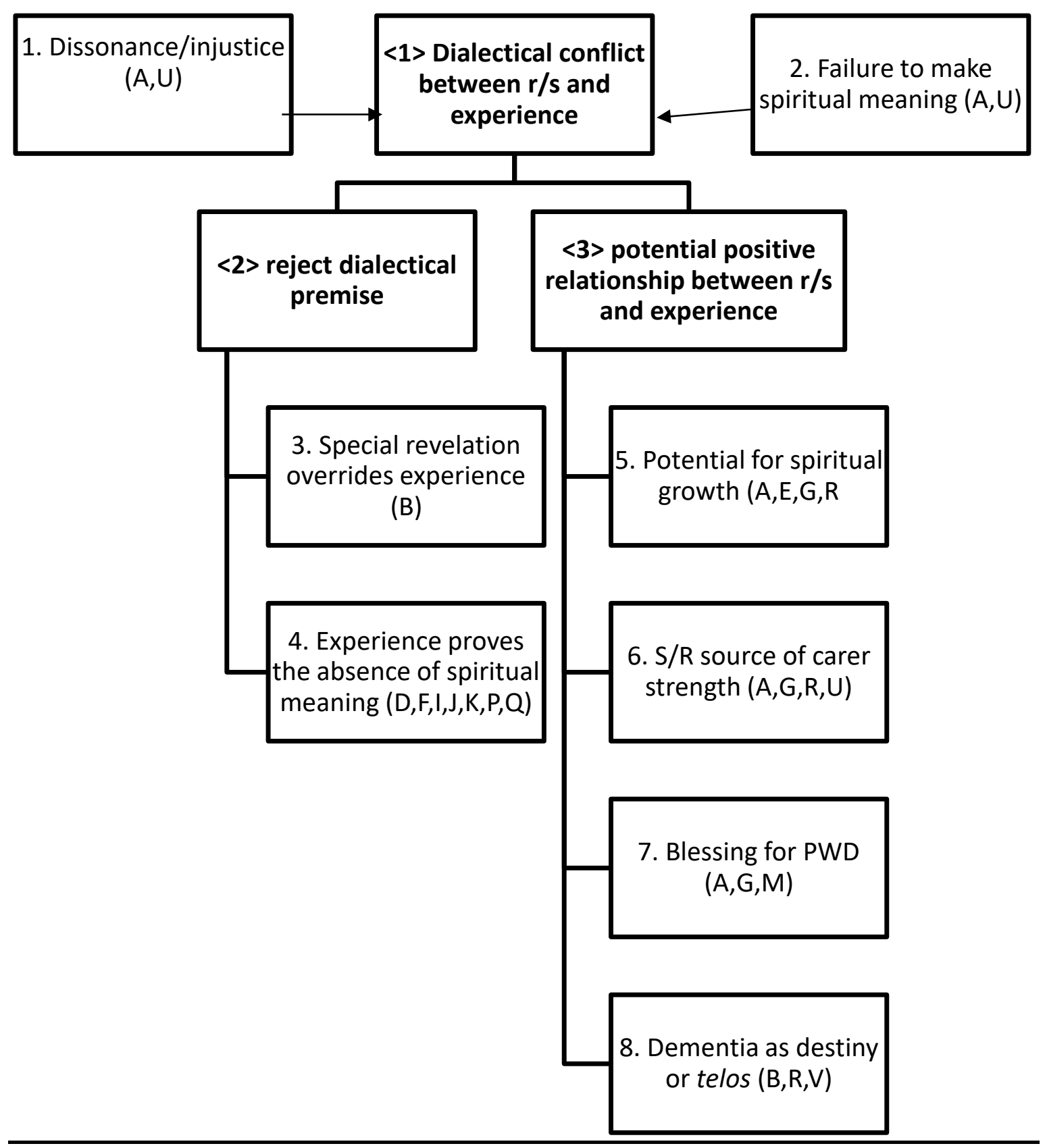

Figure 1: model of the relationship between themes (numbers refer to themes from Table 2; letters to contributors)

As will be seen from this figure, there is no single satisfactory answer to the original participant's request for "thoughts which lend a spiritual perspective to going through dementia". Indeed, the fact that some participants' contributions appear under more than one heading in Figure 1 demonstrates that an individual 
may adopt several perspectives at once. From the participants' own narratives, it is clear that these are not logically-exclusive explanatory strategies but attempts within a conversational context to reflect upon complex and emotionally-rich experiences, and therefore cannot be sorted into categories with any degree of precision.

\section{Conclusions}

It would be dangerous to attempt to generalise from the findings of this analysis, based as it is on a small sample of self-selecting participants to an online forum who contributed over the course of a single week in 2013. The fact that the two authors had no contextual information about the participants apart from that given within the forum itself may be understood to be both a strength and a weakness of the method: it restricted the interpretative process to the text itself, but also may have rendered some material difficult to interpret. Similarly, the fact that we were unable to further question participants to seek clarification or feedback on interpretations may be a limitation of the study.

With these limitations in mind, it is nevertheless possible to draw some wider conclusions, with an appropriate degree of caution. While it is not possible to estimate what proportion of carers of people with dementia would find it relevant, the very existence of this thread on the Forum indicates that there is a number of carers whose experience of dementia constitutes a challenge to deeply-held spiritual or religious beliefs which they value and look to as a source of support, and who reach out to others for help in revising and strengthening their spiritual or religious perspective.

The finding that a relatively short and limited discussion yielded six distinct (but not mutually-exclusive) responses to the initial question demonstrates the importance of a discussion around the issues; and the repeated engagement and protracted dialogue between some participants indicates that for some, at least, the discussion itself was a potential source of strength and reassurance. But it also shows that there is no single response which will address the spiritual or religious concerns of all carers.

In the light of the substantial body of research that links carers' spirituality and religion to their resilience and wellbeing (e.g.Spurlock, 2005), the fact that some carers actively reappraise their spiritual and religious resources and seek new ways to make sense of their experience deserves some attention: it is reasonable to conclude that their spiritual struggles are either positively or negatively affecting their wellbeing and capacity to care. This raises the question of how relevant agencies can support carers' spiritual or religious concerns. In a secular context such as the United Kingdom, such recommendations rightly raise 
some anxiety: it is not the place of a statutory or fourth-sector organisation to adopt or support a particular religious or (non-religious) perspective.

However, the forum analysed here gives some reassurance in this regard. The context in which the discussion takes place is clearly post-religious, and particular religious positions are given no privileged status. The plurality of proffered responses implies that the priority is not to judge or attempt to give a single 'answer', but to acknowledge, listen to and support those carers for whom these issues may be urgent, distressing and fundamental to their sense of wellbeing. Finally, the analysis of the structure of participant contributions suggests that carers will tend to find spiritual meaning by telling and reflecting upon a narrative of their own experience: the role of others is to validate their questions, rather than to attempt to provide answers.

The research thus sketches the outlines of a framework within which organisations supporting carers may develop a strategy for including spiritual support within their range of services. Further research is required to determine how such a strategy could be implemented in practice.

\section{References}

Acton, G. J. and Miller, E. W. (2003) 'Spirituality in caregivers of family members with dementia', Journal of Holistic Nursing. 21(2), pp. 117-130

Albinsson, L. and Strang, P. (2003) 'Existential concerns of families of late-stage dementia patients: questions of freedom, choices, isolation, death, and meaning', Journal of palliative medicine. 6(2), pp. 225-235.

British Psychological Society (2017) Ethics Guidelines for Internet-mediated Research. Leicester. Available at: www.bps.org.uk/publications/policy-andguidelines/ research-guidelines-policy-documents/researchguidelines-poli. (last accessed 3.7.18)

Damásio, B. F. and Koller, S. H. (2015) 'Complex experiences of meaning in life: Individual differences among sociodemographic variables, sources of meaning and psychological functioning', Social Indicators Research. 123(1), pp. 161-181. Desai, K. M. and Pargament, K. I. (2015) 'Predictors of Growth and Decline Following Spiritual Struggles', The International Journal for the Psychology of Religion. 25(1), pp. 42-56

Elgesem, D. (2002) 'What is special about the ethical issues in online research?', Ethics and Information Technology. 4(3), pp. 195-203.

Eysenbach, G. and Till, J. E. (2001) 'Ethical issues in qualitative research on internet communities', Bmj. 323(7321), pp. 1103-1105.

Fabrício, B. et al. (2011) 'Qualitative Analysis of Discussion Forums', 
International Journal of Computer Information Systems and Industrial Management Applications, 3, pp. 2150-7988.

Farran, C. J., Paun, O. and Elliott, M. H. (2003) 'Spirituality in Multicultural Caregivers of Persons with Dementia', Dementia. 2(3), pp. 353-377. Heelas, P., Woodhead, L., Seel, B., Tusting, K., \& Szerszynski, B. . (2005) The Spiritual Revolution: Why Religion is Giving Way to Spirituality. Oxford: Blackwell.

Heo, G. J. and Koeske, G. (2013) 'The Role of Religious Coping and Race in Alzheimer's Disease Caregiving.', Journal of Applied Gerontology. 32(5), pp. 582-604.

Hinton, L. et al. (2010) 'Religious and spiritual dimensions of the Vietnamese dementia caregiving experience.', Hallym International Journal of Aging, 10(2), pp. 139-60.

Holtz, P., Kronberger, N. and Wagner, W. (2012) 'Analyzing Internet forums a practical guide', Journal of Media Psychology, 24(2), pp. 55-66.

Im, E.-O. and Chee, W. (2006) 'An Online Forum as a Qualitative Research Method', Nursing Research, 55(4), pp. 267-273.

Jowett, A. (2015) 'A Case for Using Online Discussion Forums in Critical Psychological Research', Qualitative Research in Psychology, 12(3), pp. 287297.

Kaufman, S. and Whitehead, K. A. (2016) 'Producing, ratifying, and resisting support in an online support forum', Health: An Interdisciplinary Journal for the Social Study of Health, Illness and Medicine, 22(3) pp.223-239

Keck, D. (1996) Forgetting Whose We Are. Nashville, TN. Abingdon Press. Kozinets, R. V (2015) Netnography - redefined. London. Sage

Lopez, J. et al. (2012) 'Spirituality and self-efficacy in dementia family caregiving: trust in God and in yourself', International Psychogeriatrics. 24(12), pp. 19431952.

Netto, N. R., Jenny, G. Y. N. and Philip, Y. L. K. (2009) 'Growing and gaining through caring for a loved one with dementia', Dementia, 8(2), pp. 245-261. Paulus, T., Warren, A. and Lester, J. N. (2016) 'Applying conversation analysis methods to online talk: A literature review', Discourse, Context and Media. 12, pp. 1-10.

Paun, O. (2004) 'Female Alzheimer's Patient Caregivers Share Their Strength', Holistic Nursing Practice. 18(1), pp. 11-17.

Pietkiewicz, I. et al. (2014) 'A practical guide to using Interpretative Phenomenological Analysis in qualitative research psychology', Czasopismo Psychologiczne Psychological Journal, 20(1), pp. 7-14.

Rathier, L. A. et al. (2015) 'Religious coping in caregivers of family members with dementia', Journal of Applied Gerontology. 34(8), pp. 977-1000. 
Ravari, A., Mirzaei, T., Salamizadeh, A., \& Askari Majdabadi, H. . (2017) 'Effect of the spiritual care training on anxiety reduction in home caregivers of the elderly with alzheimer disease', Koomesh, pp. 467-474.

Sanders, S. (2005) 'Is the glass half empty or half full? Reflections on strain and gain in caregivers of individuals with Alzheimer's disease.', Social Work in Health Care. 40(3), pp. 57-73.

Schnell, T. (2009) 'The Sources of Meaning and Meaning in Life Questionnaire (SoMe): Relations to demographics and well-being', Journal of Positive Psychology, 4(6), pp. 483-499.

Schnell, T., Gerstner, R. and Krampe, H. (2018) 'Crisis of meaning predicts suicidality in youth independently of depression', Crisis. (advance online publication) available from http://psycnet.apa.org/record/2018-08638-001 Smith, A. L. et al. (2001) 'Caregiver needs: a qualitative exploration.', Clinical Gerontologist, 24(1/2), pp. 3-26.

Smith, A. L. (2001) 'The stages of caregiving: The spiritual connection for the journey with Alzheimer's', American journal of pastoral counseling. 4(3), pp. 1940.

Smith, A. L. and Harkness, J. (2002) 'Spirituality and meaning: A qualitative inquiry with caregivers of Alzheimer's disease', Journal of family psychotherapy. 13(1-2), pp. 87-108.

Smith, J. A., Flowers, P. and Larkin, M. (2009) 'Interpretative phenomenological analysis: Theory, method and research.' London: Sage.

Spurlock, W. (2005) 'Spiritual Well-Being and Caregiver Burden Alzheimer's Caregivers Geriatric Nursing, 26(3), p.154-161

Stuckey, J. C. (2003) 'Faith, Aging, and Dementia. Experiences of Christian, Jewish, and Non-Religious Spousal Caregivers and Older Adults', Dementia. 2(3), pp. 337-352.

Sun, F. and Hodge, D. R. (2014) 'Latino Alzheimer's Disease Caregivers and Depression: Using the Stress Coping Model to Examine the Effects of Spirituality and Religion', Journal of Applied Gerontology. 33(3), pp. 291-315 Wilks, S. E. and Vonk, M. E. (2008) 'Private prayer among Alzheimer's caregivers: mediating burden and resiliency', Journal of Gerontological Social Work. 50(3-4), pp. 113-131. 